\title{
Governance of Technology and Innovation Policy Mix: The Estonian Experience Since 2000
}

\author{
Selda Gorkey-Aydinoglu ${ }^{1} \&$ Zekai Ozdemir ${ }^{2}$ \\ ${ }^{1}$ Faculty of Economics and Administrative Sciences, Isik University, Istanbul, Turkey \\ ${ }^{2}$ Faculty of Economics, Istanbul University, Istanbul, Turkey \\ Correspondence: Selda Gorkey-Aydinoglu, Faculty of Economics and Administrative Sciences, Isik University, \\ Istanbul, Turkey. Tel: 90-216-528-7103. E-mail: seldagorkey@isikun.edu.tr
}

\author{
Received: March 3, 2015 Accepted: April 4, 2015 Online Published: May 14, 2015 \\ doi:10.5539/res.v7n7p144 URL: http://dx.doi.org/10.5539/res.v7n7p144
}

\begin{abstract}
Technology and innovation policies began to be implemented in Estonia in the 2000s, a time when the country's governance system for technology and innovation policy was still weak. However, by building strong institutions, increasing budgets for research, and designing successful policies, rapid development of the governance system resulted in a short span of time. Successful implementation of European-type innovation policies helped to build strong governance as well. This study examines technology and innovation policies and the associated governance system in Estonia with a focus on the post-2000 period. Even though the country is generally accepted as a success story for strengthening its governance, and for the Europeanization of its technology and innovation policy, it still faces major problems. These problems will erode the strong governance system if they remain unsolved. Estonia is coping with relative worsening of the main outputs of technology policies, and the effects of the 2008-2009 economic crisis made the downturn more evident. Hence, defining and evaluating these weaknesses would be valuable for the country in order to pursue rapid development, which peaked in 2007-2008 and has slowed down since.
\end{abstract}

Keywords: governance, technology policy mix, innovation policy mix, Estonia

\section{Introduction}

Technology and innovation policies are at the core of technological progress and, hence, of economic development. The success of such policies depends on effectiveness of the governance process. Governance of any policy includes design, implementation, monitoring and evaluation. However, the use of the term for technology and innovation policy is not limited to those processes. Governance of technology and innovation policy does not only include administrative capability, but also emphasizes the existence and effective implementation of systems approach in a country (Laranja, 2012). The collaboration of various units and actors, and a proper division of tasks among them, are essential in order to collect and deepen knowledge of the systems approach (Patel \& Pavitt, 1994; Metcalfe, 1995). Governance of technology and innovation therefore must place a great emphasis on integration of public research, business enterprises and non-profit institutions in order to pursue effective policies. The organizational structures and strength of institutions are among the main determinants of success (Kattel, 2004).

The Estonian experience in governance of technology and innovation policy has been regarded as a success story since the governance structure was rapidly improved (Kalvet, 2012). The country started to implement a technology and innovation policy at the beginning of 2000s, but it had weak governance at that time. The country then built a strong governance system in a very short span of time. Despite the challenges that Estonia still faces, the developments have been significant, especially between 2005 and 2010. However, studies solely focused on Estonian technology and innovation governance are very limited in number. Some of the experiences Estonia faced can be an example to other Central and Eastern European (CEE) countries which aim to build a strong national innovation system. The evolution of the relevant policies in Estonia, and assessing the most recent situation would therefore contribute to the literature. This study aims at examining the structure and the development of technology and innovation policy governance in Estonia from 2000 to the present. This study differs from the existing ones in that it also includes the most recent developments and deficiencies the country faces. Even though Estonia is generally accepted as a success story, the country still faces major challenges that 
may affect the success of its governance if they remain unsolved. The effects of the 2008-2009 economic crisis make these challenges more visible as well. Reflection of such weaknesses would also contribute to full assessment of the current state.

The relevant studies of the literature can be classified into two groups. The first group consists of studies that focus on governance of technology and innovation policies only in Estonia. The other group examines the subject for a group of countries, such as Baltic countries, CEE countries, or transition countries; these studies reflect the current state in Estonia, as well as the states in other countries. The studies that fall into first group resemble the scope of this current study. The major studies in this group are: Kattel (2004), Polt (2007), Kalvet (2010), and Karo (2010). The major studies of the second group are: Radosevic (2004), Suurna and Kattel (2010), and Karo (2011). The Kattel (2004) and Radosevic (2004) studies the periods at the beginning of 2000s, when Estonia had not yet improved its governance. Hence, the former study emphasizes Estonia's shortcomings in governance policies. The latter study points out a conflict for the country: despite possessing higher catch-up capability than other CEE countries, Estonia had a relatively weaker research system. Polt (2007) analyzes Estonian R\&D and innovation system in detail and mainly includes comments on the policy papers. Kalvet (2010) focuses on the implications of the cohesion policy, and Karo (2010) discusses whether governance in Estonian innovation policy has been a success. It also puts an emphasis on policy as it evolves from a public good basis to a network basis.

This study aims to evaluate the development of technology and innovation governance in Estonia by examining in detail the policies and structure of the institutions. The study also includes and evaluates the economic success of these policies by examining the relevant indicators. This study aims to seek answers to the following questions: In what ways can governance in technology and innovation policy be regarded as a success story in Estonia? What are the main challenges that may cause governance in relevant policies to lose strength? The study also aims to find an answer to the following question, but with a secondary purpose: Can the Estonian experience be an example for other Central and Eastern European (CEE) countries?

The study is organized as follows. Section 2 examines in detail the policy documents, policies implemented, and the organizational structures of institutions responsible for implementation. Section 3 analyzes the main indicators of relevant policy measures since they reflect the economic success of such policies, and section 4 concludes.

\section{The Development of the Governance of Technology and Innovation Policy Mix in Estonia}

\subsection{Overview of Technology and Innovation Policy Governance}

Estonia gained independence in 1991, following the collapse of Soviet Union. The 1990s were mostly the years when structural changes took place and a legal basis for policymaking was built. The Organization of the Research Act was approved by the parliament in 1994, and the expanded version of the law, the Organization of Research of Development Act, was confirmed by the parliament in 1997. The organizational structure of the research institutes was re-organized in those years (Estonian Research and Development Council, 2002). Most academic institutions were transformed into universities in 1997 and 1998 (Karo, 2011).

Even though 1990s were the years of structural change in the research system, the policy designs and implementations in science, technology and innovation only began in the 2000s. Hence, this study focuses on the post-2000 period. The first program implemented was Knowledge-based Estonia: Estonian Research and Development Strategy 2002-2006 (KBE I). It was prepared based on the Finnish experience since Finland's technology and innovation policy was regarded as among the best (Kattel, 2004). The strategic objectives were to deepen and contemporize knowledge accumulation, and to provide a more competitive environment for enterprises. In order to reach these objectives, information technologies, biomedicine, and material technologies were determined as the key areas to be developed during the program (Estonian Research and Development Council, 2002). At the start, Estonia's governance was disorganized. The country had below-average indicators for technological progress and a weak R\&D structure, especially in the business sector (Kattel, 2004; Radosevic, 2004).

KBE I was extended with another program, Knowledge-based Estonia: Estonian Research and Development and Innovation Strategy 2007-2013 (KBE II). Suurna and Kattel (2010) reflects the main deficiencies of the Estonian policy-making system at the end of the KBE I and at the beginning of KBE II. The study points out major shortcomings such as: a lack of coordination between different programs, documents and ministries; Lack of specialization in technological progress; and too much bureaucracy on implementation process of policies. It also emphasizes the complex structure of the financing system as one of the major weaknesses in governance of Estonian innovation policy. 
Polt (2007) mentions in a detailed report that lack of coordination between ministries was partially solved by the date of that study. This study points out that the weaknesses of the Estonian research, development and innovation (RDI) system stem from their lack of connections with the policies of education, technology and industry. Hence, the need for strong interaction between these bodies is emphasized. The study also points out that the country's academic sector is relatively large yet distinct from the business sector. Another challenge is the weak innovation capabilities of small and medium-sized enterprises (SMEs). A great share of the firms in industry consists of SMEs, and they mostly perform in low-technology sectors. Estonian SMEs are relatively more innovative in service sectors. However, the statistics on patents are very low. Polt (2007) suggests a voucher system would overcome the shortcomings of SMEs' in innovation activities. Research institutes could perform innovation activities on behalf of SMEs and they would then be paid financial return on productive activities via a voucher system. Polt (2007) also notes that the Estonian innovation system is inadequate because the industrial structure of the country is mostly based on low R\&D sectors. The structural change in the manufacturing industry is mostly due to the expansion of the high-technology industries. However, high-technology industries in Estonia only occupy a small fraction of industry (Kilicaslan \& Taymaz, 2006).

When the KBE II document was implemented between 2007 and 2013, the main strategies were determined to be: raising the intensity of $R \& D$ relevant activities in the economy, providing an increase in the innovation capability of enterprises, and creating a society oriented to innovation for development in the long-run. Three technological areas were set to reach these strategies. These technologies were information and communication technologies, biotechnologies, and material technologies (Estonian Ministry of Education and Research, 2007). These are generic technologies, and their development increase the productivity of other industries. Since most European Union (EU) countries specified these areas as key technologies for development, the relevant policy design is referred as "European-type innovation policy." These kinds of policies contribute to both the economy and society, since they are prepared specifically for target sectors (Karo, 2011). Two other documents were implemented along with KBE II: the Action Plan for Growth and Jobs 2008-2011, and National Strategic Reference Framework 2007-2013. Both of these documents served as examples of European-type innovation policy (Kalvet, 2010). The European impact can be also seen in various policies following accession to the EU in 2004, especially as extensions of the cohesion policies (Raagmaa, Kalvet, \& Kasesalu, 2014).

Estonia had a relatively weak technology and innovation governance policy at the outset of the 2000s. Kattel (2004) points out the weak structure of technology and innovation system in Estonia. The study also emphasizes that Estonia was not successful for implementing relevant policies at that time. Since technology and innovation policies mostly have an impact on economic outcomes by time lag, the positive impact of the policies implemented were visible after a few years in Estonia. Accordingly, the development of technology and innovation policies began to be accepted as a success story from 2005. The country built a strong system of technology governance, strengthened the role of institutions as well as the responsibilities of agencies, and set up a funding system. As a consequence, main indicators that reflect economic success of the relevant policies increased substantially in a short span of time. Among several factors, the most important ones that provided the strong governance system today were policy designs and implementations that fit the country's needs, a rapid increase in R\&D expenditures, and a division of responsibilities among institutions (Karo, 2010). Depending on the European Innovation Scoreboard (2009), which produces an index for EU27 countries depending on 29 indicators, Estonia was ranked in the innovation followers group. This is the second best group in the study, following the innovation leaders category. The findings of the study indicate the rapid growth of Estonia among other CEE countries (Pro Inno Europe, 2009). However, the Estonian economy was affected by the global economic crisis, so its main indicators of technological development have decreased in the recent years. These followed a severe decline in spending for R\&D activities (Inno-Policy Trendchart, 2009). The budget decreases devoted to R\&D activities may cause more decline in economic outputs of technology and innovation policies. In other words, budget decreases and declines in economic outputs may mutually affect each other, and hence this process may result in lack of sustainability in Estonian RDI system that reached its peak in 2007-2008.

The documents currently in the implementation process are Knowledge-based Estonia: Estonian Research and Development and Innovation Strategy: 2014-2020 (KBE III), Estonian Entrepreneurship Growth Strategy: 2014-2020, and Estonian Lifelong Learning Strategy: 2014-2020 (OECD, 2014). The former, KBE III, is the main document that sets targets to be achieved by 2020 and four main objectives. These objectives are: to make Estonia a place where high level of research is conducted, to conduct R\&D activities that fulfill needs of both the economy and the society, to conduct R\&D activities that deepen the country's knowledge base, and to enable Estonia to participate in international RDI collaborations. KBE III sets statistical targets to be achieved by 2020 . These targets are: $3 \%$ of GDP devoted to R\&D investment, with business sector contributing $2 \%$; rank of at least 
ten in the EU Innovation Scoreboard; and increased productivity per employed person, so that the productivity level is equivalent to $80 \%$ of the EU average. The main document also includes a SWOT analysis of the current RDI system in Estonia. Some of the weaknesses of the system found were: lack of coordination between units, lack of collaboration between academia and industry, and the performance of research on a project basis rather than an output basis. KBE III is closely linked with other policy documents that are currently in implementation (Parliament of Estonia, 2014). The last document was prepared very recently, so time is needed to evaluate it and watch the most recent indicators.

\subsection{Institutions and Financing}

Two major Estonian ministries are in charge with technological activities. Each is responsible from different aspects of the governance of technology and innovation policy mix. The Ministry of Education and Research (MER) is the main body concerned with development and financing of research policy. It is mostly focused on public research. The Ministry of Economic Affairs and Communications (MEAC) is charged with financing and carrying out development policies. This ministry is primarily responsible for business-oriented research; specifically the Technology and Innovation division of MEAC is mainly responsible for related policies. These two ministries collaborate with other ministries when necessary. However, the coordination has often been deemed disorganized (Kattel, 2004; Polt, 2007). Another institution that is responsible for implementing technology and innovation policies is the Research and Development Council, which was established in 1990. It advises the government on policies regarding strategic R\&D areas (Suurna \& Kattel, 2010; Research and Development Council, 2002).

Public research activities are mainly financed by MER, which has three sub-divisions. Each is responsible for different types of funding. These sub-divisions are the Council of Scientific Competence, Estonian Science Foundation, and Archimedes Foundation. The first division is mainly in charge of target financing; the second mostly deals with delivering grants to researchers; and the last is charged with transferring EU funds (Karo, 2010). Hence, these units serve the development of innovation policy from the point of research-based, educational and technological aspects (Suurna \& Kattel, 2010).

There are also several governmental agencies charged with design and implementation of technology and innovation policy. They are mostly specialized in distinct work fields. Enterprise Estonia (EE), KREDEX and Development Fund are responsible for business development processes, especially for SMEs (Suurna \& Kattel, 2010:15). Among these, EE supports projects prepared on research and product development, and delivered to universities, research institutes, and research laboratories in the business sector. These funds are provided by MEAC (Tiits, Kattel, Kalve, \& Kaarli, 2003; Kattel, 2004). EE also funds national programs such as the SPINNO Program, Competence Center Program, and Innovation Awareness Program. The SPINNO Program was prepared for universities and research institutes with the aim to strengthen their links with business enterprises (Polt, 2007). Competence Centers Program, launched in 2003, aim to promote interactions and collaborations between the public science and business sectors. The program is administered by EE, and it consists of several centers focused on different technologies, such as biotechnology, nanotechnology, information and communication technology, and machine technologies (Karo, 2010; Kattel, 2004). The Centers of Excellence were established with the purpose of supporting high-level research and deepening research cooperation. There are seven centers currently in Estonia, and they are funded by European Regional Development Fund (Estonian Research Portal, online). Another unit that funds business research activities is the Development Fund. The main purpose of this fund is to provide venture capital to start-up enterprises, and to advise them on running the business (Polt, 2007). Since the business sector mostly consists of SMEs in Estonia, such a fund contributes to knowledge creation.

\section{Economic Success of Governance of the Technology and Innovation Policy Mix in Estonia}

\section{$3.1 R \& D$ Activities and Innovativeness}

The resources devoted to R\&D activities have increased remarkably since 2005 in Estonia. Gross expenditures on R\&D (GERD) rose from $0.60 \%$ of GDP in 2000 to $0.93 \%$ of GDP in 2005, to $1.63 \%$ of GDP in 2010, and to $2.18 \%$ in 2012 (The World Bank Data, online). The Organization for Economic Cooperation and Development (OECD , 2014) also emphasizes this rapid growth in GERD, which averaged $14.2 \%$ annually between 2007 and 2012. However, it then fell to $1.74 \%$ of GDP, as the relevant indicator has shown a similar effect due to the global economic crisis in most other countries (Inno-Policy Trendchart, 2009). Business enterprise expenditures on R\&D (BERD) in Estonia was $0.1 \%$ of GDP, however it accelerated rapidly after 2005, reaching $1.08 \%$ of GDP in 2012 from a low level of $0.33 \%$ in 2005 . R\&D expenditures in the higher education sector in 2012 were $0.69 \%$ of GDP in Estonia. In the same year, $0.10 \%$ of GERD was financed from abroad (Eurostat, online). R\&D 
expenditures on health retained an important place in government R\&D funding (OECD, 2012). The rapid increase in the statistics clearly shows that the budget devoted to relevant activities were much higher especially in the post-2005 period. Hence, the outcomes of relevant policies began to be visible by that time.

The distribution of BERD by economic activities show funding priorities of a country, since it is mainly specified by technology and innovation policies. BERD allocated the most funds in 2011 to chemicals and minerals, information and communication services and R\&D services. In manufacturing, BERD in low and medium-low technology sectors accounts for $90.62 \%$ of total manufacturing BERD; this ratio makes it clear that business R\&D specialization in high and medium-high technology sectors are remarkably low in Estonia compared to other developed economies (OECD, 2013). As a consequence, the ratio of high-technology exports to manufactured exports is low. This ratio was $10.74 \%$ in 2012, whereas the EU average was $15.44 \%$ in the same year (The World Bank Data, online) Rapid increase in the relevant ratio is essential, since it typically shows the structural change of manufacturing industry in any country.

Estonian firms mostly consist of SMEs, which mostly operate in low-technology sectors. Hence, they conduct very little innovative activities (Polt, 2007). Innovation activities are mostly conducted by large firms, but number of large firms in Estonia is very low. Depending on the results of the Community Innovation Survey (CIS), $70 \%$ of the large firms stated that they undertook product or process innovation, or both activities, between 2008 and 2010. However, the percentage was only 40.7\% for SMEs. In 2011, 89.10\% of the firms in the business sector reported that they received financial support from government to conduct R\&D activities. These financial incentives are generally referred to as government-financed BERD, and may be in the form of grants, loans or procurement contracts (OECD, 2013).

Venture capital, essential for the development of the innovation capability, is not well-developed in Estonia. It was equivalent to only $0.008 \%$ of GDP in 2012. Although, the Estonian Development Fund was initiated in 2007, the focus has been limited to expanding existing enterprises in Estonia. It does not prioritize providing venture capital to start-ups (OECD, 2013; Inno-Policy Trendchart, 2009).

\subsection{Science Base and Scientific Collaboration}

Publicly funded research is essential in Estonia, and most of the research is performed by universities. However, the academy and industry are generally lack collaboration. Despite rapid technological progress in the country, the distinct structure of these bodies remains one of the major challenges in the Estonian RDI system (Polt, 2007).

The main measure of scientific development is generally accepted as the number of scientific publications of a country. The number of scientific publications per million inhabitants was 300.3 in 1998, whereas the EU average was 618.8 in the same year. Estonia has rapidly increased its rate of in scientific publications since, with this indicator increasing to 668.3 in 2008. This value was still below the EU average of 827.7 (OECD Statistics, online). Besides having lower scientific publications per million inhabitants than the EU, the increase in the indicator was notable after 2000. Hence, the gap has narrowed substantially. The indicators of scientific publications in Estonia remain low compared to the country's relatively high competence on technology and innovation. Therefore more priority should be given on the matter in order to increase the scientific publications in number.

Estonia is very open to international collaboration in scientific and innovative activities. In Estonian academic publishing, $47.3 \%$ of all publications involved an international co-authorship in 2011 , and $34.7 \%$ of the patents were granted with international co-invention that year. Of the top-cited publications, $74 \%$ involved international collaboration between 2003 and 2011 (OECD, 2013).

\subsection{Human Capital}

Estonia was a transition country until quite recently, and it is one of the Central and Eastern European (CEE) countries. The level of human capital in these countries is higher than the development of general economic indicators reflect (Spagat, 2002). However, the transition process is now accepted as complete, and the country is ranked among developed countries (IMF, 2014). The development of human capital in Estonia has accelerated severely since 2000. Estonia was one of the EU27 nations with the fastest growth in human resources in 2009 (Pro Inno Europe, 2009). Today its several indicators on education are measured as high, and most of these proxies are much above the EU average.

Gross school enrollment ratios for tertiary education in Estonia were $56.35 \%$ in $2000,68.45 \%$ in 2005, and $76.68 \%$ in 2012. The relevant ratio for the entire EU was calculated as $66.56 \%$ in 2012 , the most recent year available in the dataset. School enrollment ratio for tertiary education for females was very high in 2012, at $93.29 \%$; whereas 
the EU average was only $74.81 \%$ (The World Bank Data, online). Indicators of average years of schooling are generally accepted as more accurate than enrollment rates, since it is calculated by attainment levels. The most commonly used data for this indicator is that of Barro and Lee (2013). It shows that, Estonia had an average of 11.73 years of total schooling for population over 25 years old in 2000. This value increased to 11.90 years in 2005, and to 12.01 years in 2010. This is the second high indicator among CEE countries, where the highest indicator belongs to Czech Republic with 12.32 years in 2010. The EU average was calculated as 10.52 year in the same year. The average years of schooling in Estonia can also be analyzed by education level in the Barro and Lee (2013) dataset as: 0.92 years of tertiary schooling, 5.11 years of secondary, and 5.98 years of primary, on average in 2010. These values clearly show that school enrollments and attainment levels are remarkably high in the country. Estonia devotes high expenditures to education, with $5.16 \%$ of GDP; however, the ratio is slightly below the EU average of $5.25 \%$ of GDP in 2010 . However the relevant indicator at the tertiary level is $1.29 \%$ of GDP, and slightly above the EU average of $1.27 \%$ of GDP in the same year (Eurostat, online).

Test scores are accepted as one of the best proxies for student achievements. They also present general information on the quality of the schooling system (Hanushek \& Kim, 1995). These indicators are significant since they reflect the success and the skills of the next generation. There are many tests, however they vary in country and time coverage. Altinok et al. (2013) developed a new database that is calculated by all existing test from 1965 to 2010 for a broad panel of 111 countries. The test results of the Estonian students were very high, with 594 points, whereas the average of the EU and the G7 countries was 565 and 584, respectively. Female students performed better than males, and the students participating from urban areas earned higher points than those from rural areas, as expected. The score gap between urban and rural areas was remarkably very low, compared to other countries included in the database.

Indicators of persons employed in science and technology relevant jobs are quite a significant measure. The ratio was $32.9 \%$ in 2012, and $6.3 \%$ of total employed persons was scientists and engineers (Eurostat, online). Women constituted $63.9 \%$ of the workers in science and technology related jobs in the same year. That percentage is remarkably higher than most of the other developed economies (OECD, 2013).

Depending on the Project of Careers of Doctorate Holders, which is carried out by the OECD, UNESCO and Eurostat, the number of doctorate holders in Estonia was 2,794 persons in 2006 , and only $11.45 \%$ of these persons were under 35 years old. Of the total Estonian doctorate holders, $36.83 \%$ were females. There is a need for an updated evaluation of the current situation of doctorate holders. The percentage of the doctorate graduates from science-related disciplines was 36.4\% of all doctorate graduates in 2011 (OECD, 2013). OECD (2012) points out that the number of doctorate holders in science and engineering disciplines should be higher and that government policies should encourage students to pursue studies in these disciplines.

The indicators that present the charactersictics of human capital in Estonia clearly shows that Estonia is rich in qualified human resource. The relevant proxies in Estonia are one of the highest in CEE region, and quite close to those of developed countries.

\section{Conclusion}

The 1990s were the years of necessary structural adjustment to build a strong backbone for governance of technology and innovation policies. Designs and implementation of these policies started in the 2000s. The country had a relatively weak governance and RDI system at the beginning; however, made progress in a short span of time. Despite some weaknesses, today the early years are accepted as a success story. This study aims at examining in detail the technology and innovation policies and the associated governance in Estonia since 2000. Hence, the study analyzes policy documents, the organization of institutions as well as the funding system. The study also includes main outputs of the policies, thus indicating the economic success of such policies.

The study concludes that the Estonian governance system was successful, especially up to 2010. However, it still faces major challenges. The study answers the first research question by finding out that success, which peaked in 2007-2008, was mostly due to: implementation of policies of the Finnish experience, the best model in Europe; choosing policy measures that fit the country's needs; rapid increases in R\&D expenditures; construction of strong and well-organized institutions; and the funding system. This rapid development faced a slowdown after 2010, due to the crisis that also affected the main outputs with a time lag of couple years. Specifying these major challenges answers the second research question. The major challenges the country faces today are: low R\&D industrial intensity since SMEs undertake very little innovative activities. The structural change of industry is mostly based on the increasing dominance of high-technology sectors, yet the afore-mentioned process indeed takes a long time. Still, Estonia should prioritize the development of high-tech enterprises. At the same time, the establishment of innovative large firms or the expansion of existing ones should contribute to growth. Another 
major weakness is that research is mostly conducted in higher education institutions, and the linkages between academia and business enterprises are weak. Hence, the country faces difficulties in the process of commercialization of research activities. The quality of research activities should also be improved to create products of higher quality. Indeed, the effects of the crisis made these challenges more visible by leading to declines in budgets of relevant research activities in the recent years. The budget decreases may affect economic outcomes of relevant policies negatively, and this process may threaten the success of the Estonian RDI strategy that reached its peak just before the economic crisis.

The study also aims to answer another question: whether the experience Estonia faced can be an example for other CEE countries. This study concludes that Estonia can indeed be a model for other countries, especially for its success in designing accurate policies, building a strong governance system, and increasing budgets for R\&D activities. However, it should be noted that the challenges the country faces now have remained unresolved for a long time; it is essential to provide solutions in order to pursue rapid development after the post-2010 decline.

\section{References}

Altinok, N., Diebolt, C., \& Demeulemeester, J. L. (2013). A new international database on education quality: 1965-2010 (Les Documents de Travail de l'IREDU Working Papers). Institut de Recherche sur l'Education.

Barro, J., \& Lee, J. W. (2013). A new data set of educational attainment in the world, 1950-2010. Journal of Development Economics, 104, 184-198. http://dx.doi.org/10.1016/j.jdeveco.2012.10.001

Estonian Ministry of Education and Research. (2007). Knowledge-based Estonia: Estonia research and development and innovation strategy 2007-2013. Tartu, Estonia.

Estonian Research and Development Council. (2002). Knowledge-based Estonia: Estonia research and development strategy 20020-2006. Tallinn, Estonia.

Estonian Research Portal. (2015, January). National Cooperation: Centers of Excellence. Retrieved from https://www.etis.ee/Portaal/srk.aspx?lang=en

Eurostat. (2014, December). Eurostat Database. Retrieved from http://ec.europa.eu/eurostat/data/database

Hanushek, E. A., \& Kim, D. (1995). Schooling, labor force quality, and economic growth (NBER Working Paper, 5399).

IMF: International Monetary Fund. (2014). World economic outlook-Recovery strengthens, remains uneven. Washington: IMF. http://dx.doi.org/10.5089/9781475571615.081

Inno-Policy Trendchart. (2009). Innovation Policy Progress Report-Estonia. Retrieved from $\mathrm{http} / / / \mathrm{s} 3$.amazonaws.com/zanran_storage/www.proinno-europe.eu/ContentPages/550748785.pdf

Kalvet, T. (2010). Policy paper on innovation: Estonia. Expert Evaluation Network Delivering Policy Analysis on the Performance of Cohesion Policy 2007-2013 Final Draft. A report to the European Commission Directorate.

Kalvet, T. (2012). Innovation: A factor explaining e-government success in Estonia. Electronic Government, an International Journal, 9(2), 142-157. http://dx.doi.org/10.1504/EG.2012.046266

Karo, E. (2010). Improving governance of science and innovation policies, or just bad policy emulation? The case of the Estonian R\&D system. Halduskultuur-Administrative Culture, 11(2), 174-201.

Karo, E. (2011). The evolution of innovation policy governance systems and policy capacities in the Baltic states. Journal of Baltic Studies, 42(4), 511-536.

Kattel, R. (2004). Governance of innovation policy: The case of Estonia. Trames, 8(4), 397-418.

Kilicaslan, Y., \& Taymaz, E. (2006, June). The structure of structural change. Paper presented at the DRUID Summer Conference: Knowledge, Innovation and Competitiveness: Dynamics of Firms, Networks, Regions and Institutions, Copenhagen, Denmark.

Laranja, M. (2012). Network governance of innovation policies: The technological plan in Portugal. Science and Public Policy, 39(5), 655-668. http://dx.doi.org/10.1093/scipol/scs043

Metcalfe, S. (1995). The economic foundations of technology policy: Equilibrium and evolutionary perspectives. In P. Stoneman (Ed.), Handbook of the Economics of Innovation and Technological Change (pp. 409-512). Oxford, UK and Cambridge, USA: Blackwell.

OECD. (2012). Science, technology and industry outlook 2012. OECD Publishing. 
OECD. (2013). Science, technology and industry scoreboard 2013-Innovation for growth. OECD Publishing.

OECD. (2014). Science, technology and industry outlook 2014. OECD Publishing.

OECD. (2014, November). OECD Statistics. Retrieved from http://stats.oecd.org/

Parliament of Estonia. (2014). Estonian Research and Development and Innovation Strategy 2014-2020: Knowledge-based Estonia. Retrieved from https://www.hm.ee/sites/default/files/ estonian_rdi_strategy_2014-2020_en.doc

Patel, P., \& Pavitt, K. (1994). National innovation systems: Why they are important, and how they might be measured and compared. Economics of Innovation and New Technology, 3(1), 77-95. http://dx.doi.org/10.1080/10438599400000004

Polt, W. (2007). OMC Policy mix review report: Country report Estonia. M. Turco (Observer).

Pro Inno Europe. (2009). European innovation scoreboard 2009-Comparative analysis of innovation performance. $\quad$ Retrieved from http://ec.europa.eu/enterprise/policies/innovation /files/proinno/eis-2009_en.pdf

Raagmaa, G., Kalvet, T., \& Kasesalu, R. (2014). Europeanization and de-Europeanization of Estonian regional policy. European Planning Studies, 22(4), 775-795. http://dx.doi.org/10.1080/09654313.2013.772754

Radosevic, S. (2004). A two-tier or multi-tier Europe? Assessing the innovation capacities of Central and East European Countries in the enlarged EU. Journal of Common Market Studies, 42(3), 641-666. http://dx.doi.org/10.1111/j.0021-9886.2004.00522.x

Spagat, M. (2002). Human capital, growth and inequality in transition economies (p. 499) (William Davidson Working Paper). The William Davidson Institute, Michigan Business School. http://dx.doi.org/10.2139/ssrn.332902

Suurna, M., \& Kattel, R. (2010). Europeanization of innovation policy in Central and Eastern Europe. Science and Public Policy, 37(9), 646-664. http://dx.doi.org/10.3152/030234210X12778118264459

The World Bank. (2014, December). The World Bank Data. Retrieved from http://data.worldbank.org/

Tiits, M., Kattel, R., Kalvet, T., \& Kaarli, R. (2003). Competitiveness and future outlooks of the Estonian economy: $R \& D$ and innovation policy review. Research and Development Council.

\section{Copyrights}

Copyright for this article is retained by the author(s), with first publication rights granted to the journal.

This is an open-access article distributed under the terms and conditions of the Creative Commons Attribution license (http://creativecommons.org/licenses/by/3.0/). 